\title{
The relative age effect is more than just participation bias in badminton
}

\author{
Mert Bilgiç ${ }^{1 \bowtie}$ and Erhan Devrilmez ${ }^{2}$ \\ ${ }^{1}$ Faculty of Sport Sciences, Akdeniz University, Antalya, Turkey; and ${ }^{2}$ Faculty of Sport Sciences, Karamanoğlu Mehmetbey University, \\ Karaman, Turkey
}

\begin{abstract}
Background: Annual age grouping is a widely used strategy to allocate players to age categories for more equal and fair opportunities considering the developmental differences. Although it is a well-intended strategy, certain (dis)advantages occur because of the subtle age-related differences within the same age groups. Objective: The purpose of the current study was to investigate the relative age effect among badminton players reaching the podium in the last three consecutive European U15, U17 and Junior (U19) Badminton Championships. Methods: A total of 288 medal owners from 20 countries were evaluated in the study. Chi-square $\left(\chi^{2}\right)$ goodness-of-fit tests were used to compare the obtained birth month distributions across the quartiles (Q), and odds ratios and $95 \%$ confidence intervals were calculated in order to compare quartiles with each other. Results: Statistically significant relative age effects were determined favouring relatively older athletes in the total sample $\left(\chi^{2}=82.278, p<.001\right)$. Statistically significant distribution differences were noted in both singles and doubles categories in total $\left(\chi^{2}=18.778, p<.001 ; \chi^{2}=63.815, p<.001\right.$, respectively). Striking findings were determined in Q1-Q4 and Q2-Q4 comparisons as players in Q1 and Q2 were more than five and four times as likely to reach the podium than players in Q4, respectively. Conclusions: Results of this study confirm the presence of relative age effect among award-winning badminton players which goes beyond the classical participation trends findings, and stress the importance of the issue for talent development, selection and success.
\end{abstract}

Keywords: annual age-grouping, success, youth, racket sports

\section{Introduction}

To give equal opportunity for participation, selection and success to all athletes, annual age grouping policy based on a certain cut-off date is a common strategy used in sport organizations (Musch \& Grondin, 2001). Although it is a well-intended practice, certain (dis)advantages occur because of the subtle age-related differences within the same age groups. The "relative age" refers to those chronological age differences between individuals due to the cut-off date chosen to allocate individuals, and relative age effect (RAE) is the phenomenon referring all the consequences of that (Barnsley et al., 1985). Such a strategy seems insensitive to prevent RAEs in terms of participation, selection and success in sport since an athlete born shortly after the cut-off date becomes almost 12 months older than the one born in the last month of the same year although they compete in the same age category.

In recent decades, RAE has become a focus of interest, and there exists a considerable body of literature on it in several sports like table tennis (Faber, Liu, et al., 2020; Faber, Martinen, et al., 2020) and tennis (Edgar \& O’Donoghue, 2005; Gerdin et al., 2018), and from different perspectives such as performance (Arrieta et al., 2016;
Brustio et al., 2019; Ferriz-Valero, García Martínez, et al., 2020), participation trends (Delorme \& Raspaud, 2009), dropout (Helsen et al., 1998) and success (Ferriz-Valero, Sellés-Pérez, et al., 2020). Grondin et al. (1984) are the first to propound the possible relationship between birthdates and reaching the highest level in a sport. They found a strong participation bias of hockey players in favour of those born at the beginning of the year, and suggested that this was a result of practicing cut-off date strategy to organize age categories. Similar results have been noted in literature in terms of over-representation of relatively older athletes (Arrieta et al., 2016; Delorme \& Raspaud, 2009; Turnnidge et al., 2012; Williams, 2010).

Several hypotheses have been proposed to explain RAE (Cobley et al., 2009; Musch \& Grondin, 2001), yet the explanations tend to center on maturational differences among athletes in the same age group (Bruner et al., 2011). Beunen and Malina (2008) suggested the inter-individual variations in growth, maturity and performance status among individuals of the same chronological age, particularly during pubertal years. Those variations have been identified as the underlying reasons of over-representation of relatively older athletes along with several other factors

$\triangle$ Corresponding author: Mert Bilgiç, e-mail mertbilgic@akdeniz.edu.tr, ORCID ${ }^{\circledR}$ record https://orcid.org/0000-0001-6883-3269

Article history: Received October 1 2020, Accepted February 28 2021, Published April 122021

Copyright: @ 2021 The Author(s). Published by Palacký University Olomouc. This is an open access article distributed under the terms of the Creative Commons Attribution License (https://creativecommons.org/licenses/by/4.0/), which permits unrestricted use, distribution, and reproduction in any medium, provided the original author and source are credited. This license does not cover any third-party material that may appear with permission in the article. 
like experience and sociocultural mechanisms (Cobley et al., 2009; Musch \& Grondin, 2001). These advantages are thought to be strengthened through "The Pygmalion Effect" (Hancock et al., 2013) and the role of selection processes comes as another hypothesis to explain the bias. To comply with the suggested maturational advantages, relatively older athletes are more likely to be selected in teams and attain higher quality training, coaching, equipment and experience (Helsen et al., 1998; Vincent \& Glamser, 2006).

Given that more research are required to be conducted to understand and explain the key and different tenets of RAE completely from different perspectives like participation trends, dropouts, birthplaces and theoretical frameworks. Success is such a significant tenet of elite sport that athletes have always strived for. In general, they try to do their best and reach the podium in each competition from the very early years of sport. In the relevant literature, the relationship between RAE and success was investigated among young triathletes, and a strong dominance of early born triathletes were determined with regard to reaching the podium, particularly the gold medal winners (FerrizValero, Sellés-Pérez, et al., 2020). On the other hand, Ford and Williams (2011) also looked beyond the participation bias through investigating the success from a different perspective, and no RAE was found in the birth dates of award-winning athletes in male professional team sports. However, the absence or presence of the relationship between success and RAE in individual sports and females are still grey areas to examine and in the previous studies, contradictory results have been obtained regarding being an early or late born player from different perspectives. Cobley et al.'s meta-analysis (2009) also pointed out that only $2 \%$ of participants been investigated for RAE were females. Moreover, RAE in badminton is another grey area since only a few studies included badminton with regard to RAE (Nakata \& Sakamoto, 2011, 2012) and, to the best of our knowledge, this is the first research on RAE among elite youth badminton players. Therefore, the present study aims to investigate the RAE among award-winning badminton players in three consecutive European U15, U17 and Junior (U19) Badminton Championships.

\section{Methods}

\section{Participants}

In order to avoid any coincidental results and to increase generalizability of the results, the last three consecutive European U15 (2018, 2016 and 2014), U17 (2017, 2016 and 2014) and Junior (2018, 2017 and 2015) Badminton Championships were included in the present study.

There are five disciplines in badminton which are men's singles, women's singles, men's doubles, women's doubles and mixed doubles (Badminton Europe Competition Regulations, www.badmintoneurope.com). A total of 32 medals ( 4 in singles and 8 in doubles categories) are presented to the players in the top four places in a tournament. Thereby, the sample consisted of 288 European medal owners from 20 countries in the aforementioned
European Championships. A total of 24, 13 and 12 players reached the podium in two disciplines (e.g., men's singles and mixed doubles) in European U15, U17 and Junior Championships, respectively.

\section{Design and procedure}

Following the institutional ethical approval from Clinical Studies Ethics Committee of Akdeniz University, data for country, gender, birthdate and competition discipline for each medal winner in the mentioned championships were obtained from the official websites of Badminton Europe (www.badmintoneurope.com) and Badminton World Federation (bwfbadminton.com/players). To examine RAE, birth months of players were categorized into four quartiles (Qs) in accordance with the previous RAE studies. Since the official cut-off date used in badminton is January $1^{\text {st }}, Q 1$ included players born in January, February and March, Q2 included players born in April, May and June, Q3 included players born in July, August and September, and Q4 included players born in October, November and December.

\section{Data analysis}

In order to investigate the presence of RAE, chi-square $\left(\chi^{2}\right)$ goodness-of-fit tests were conducted to compare the obtained birth month distributions across the quartiles with theoretically expected distributions, and effect size was calculated additionally. Cramer's $V$ was used for interpretation of effects (i.e., small; $V=.06-.17$; medium; $V=.18-.29$; and large; $V \geq .30$ ). As keeping in line with previous research, an assumed equal distribution across quartiles was accepted in the analyses (Helsen et al., 2005; Raschner et al., 2012). Odds ratios and 95\% confidence intervals were used to compare quartiles with each other. Moreover, each medal owner was included in the study, and considering the different playing characteristics of singles and doubles, analyses were conducted for both categories and in total too. All statistical analyses were conducted using IBM SPSS Statistics (Version 23.0; IBM, Armonk, NY, USA) and the statistical significance was set at $p<.05$.

\section{Results}

The quarterly birthdate distributions, results of $\chi^{2}$ analyses and Cramer's $V$ calculations of medal winners in the last three European U15, U17 and Junior Badminton Championships are presented in Table 1.

For each age category, gender and participants as a whole, $\chi^{2}$ analyses revealed significantly over representation of players born shortly after the cut-off date on the podium compared to those born shortly before the cut-off date. Regarding age, the RAE showed a larger effect size in U15 players, and in total, a decreasing trend was noted in terms of effect size values. The peak of RAEs has been noted in U15 females where 25 medals $(52.1 \%)$ were won by players in Q1 while only 4 medals $(8.3 \%)$ were won by players in Q4 $\left(\chi^{2}=23.833, p<.001, V=.41\right)$. On the other hand, the lowest of RAEs has been determined in Junior males $\left(\chi^{2}=10.167, p=.017, V=.27\right)$. Regarding gender, higher values in $\chi^{2}$ tests and effect sizes were 
determined among female medal owners favouring early born players.

In Table 2, considering the singles (men's and women's) and doubles (men's, women's, and mixed) categories, statistically significant over-representation of Q1 players were determined in both categories $\left(\chi^{2}=18.778, p<.001\right.$, $V=.29 ; \chi^{2}=63.815, p<.001, V=.31$, respectively). Considering the effect sizes, the peak of RAE by category was determined in U15 Singles that 13 Q1 players (54.2\%) reached the podium while only $1 \mathrm{Q} 4$ player $(4.2 \%)$ reached the podium $\left(\chi^{2}=12.667, p=.005, V=0.42\right)$. Moreover, the findings show that statistical significance is higher in doubles compared to singles.

Along with significant RAEs and decreasing trend of effect sizes with age presented in Table 1, Table 3 shows odds ratios determined between quartiles by categories and in total. Significant odds ratios are noted mostly in Q1 vs. Q4 and Q2 vs. Q4 comparisons and in some of Q3 vs. Q4 comparisons. In total, it could be suggested that players in Q1, Q2 and Q3 are more than five, four and two times as likely to reach the podium than players in Q4 respectively.
Figure 1 presents the quarterly distribution of medal winners according to the type of medals, age categories, and singles and doubles categories. In total, 34 gold, 28 silver and 61 bronze medals were won by players in Q1 while only 7 gold, 4 silver and 10 bronze medals were won by players in Q4.

\section{Discussion}

The purpose of the current study was to investigate the role of RAE among award-winning badminton players in three consecutive European U15, U17 and Junior (U19) Badminton Championships to get a deeper understanding of the role of RAE apart from just participation trends as in many studies in the literature. Taken together, a skewed distribution was determined among award-winning players across all age categories favouring relatively older players which fairly supports the current body of literature. Moreover, a decreasing trend of RAE was noted with increasing age, and stronger bias was determined among female medal winners compared to males.

While discussing the bases of RAE, a developmental systems model was suggested to reach a deeper understanding

Table 1 Quarterly distribution of award-winning athletes' birth months in European U15, U17 and Junior (U19) Badminton Championships

\begin{tabular}{|c|c|c|c|c|c|c|c|c|}
\hline & Q1 & Q2 & Q3 & Q4 & Total & $\chi^{2}$ & $p$ & Cramer's $V$ \\
\hline \multicolumn{9}{|l|}{ Females } \\
\hline U15 & $25(52.1)$ & $14(29.2)$ & $5(10.4)$ & $4(8.3)$ & 48 & 23.833 & $<.001$ & .41 \\
\hline U17 & $22(45.8)$ & $13(27.1)$ & $10(20.8)$ & $3(6.3)$ & 48 & 15.550 & .001 & .33 \\
\hline Junior (U19) & 19 (39.6) & $17(35.4)$ & $8(16.7)$ & $4(8.3)$ & 48 & 12.833 & .005 & .30 \\
\hline Total & $66(45.8)$ & $44(30.6)$ & $23(16.0)$ & $11(7.6)$ & 144 & 48.833 & $<.001$ & .34 \\
\hline \multicolumn{9}{|l|}{ Males } \\
\hline U15 & 23 (47.9) & $15(31.3)$ & $7(16.4)$ & $3(6.3)$ & 48 & 19.667 & $<.001$ & .37 \\
\hline U17 & 20 (41.7) & $14(29.2)$ & $10(20.8)$ & $4(8.3)$ & 48 & 11.333 & .010 & .28 \\
\hline Junior (U19) & $14(29.2)$ & $18(37.5)$ & $13(27.1)$ & $3(6.3)$ & 48 & 10.167 & .017 & .27 \\
\hline Total & $57(39.6)$ & $47(32.6)$ & $30(20.8)$ & $10(6.9)$ & 144 & 35.389 & $<.001$ & .29 \\
\hline \multicolumn{9}{|l|}{ Total } \\
\hline U15 & $48(50.0)$ & $29(30.2)$ & $12(12.5)$ & $7(7.3)$ & 96 & 43.083 & $<.001$ & .39 \\
\hline U17 & $42(43.8)$ & $27(28.1)$ & $20(20.8)$ & $7(7.3)$ & 96 & 26.583 & $<.001$ & .30 \\
\hline Junior (U19) & $33(34.4)$ & 35 (36.5) & 21 (21.9) & $7(7.3)$ & 96 & 20.833 & $<.001$ & .27 \\
\hline Total & $123(42.7)$ & 91 (31.6) & $53(18.4)$ & $21(7.3)$ & 288 & 82.278 & $<.001$ & .31 \\
\hline
\end{tabular}

Note. Q1, Q2, Q3, Q4 = birth quarters.

Table 2 Quarterly distribution of award-winning athletes' birth months by categories in European U15, U17 and Junior (U19) Badminton Championships

\begin{tabular}{|c|c|c|c|c|c|c|c|c|}
\hline & Q1 & Q2 & Q3 & Q4 & Total & $\chi^{2}$ & $p$ & Cramer's V \\
\hline \multicolumn{9}{|l|}{ Singles } \\
\hline U15 & $13(54.2)$ & $5(20.8)$ & $5(20.8)$ & $1(4.2)$ & 24 & 12.667 & .005 & .42 \\
\hline U17 & $8(33.3)$ & $8(33.3)$ & $6(25.0)$ & $2(8.3)$ & 24 & 4.000 & .261 & .24 \\
\hline Junior (U19) & $9(37.5)$ & $9(37.5)$ & $4(16.7)$ & $2(8.3)$ & 24 & 6.333 & .096 & .30 \\
\hline Total & $30(41.7)$ & $22(30.6)$ & $15(20.8)$ & $5(6.9)$ & 72 & 18.778 & $<.001$ & .29 \\
\hline \multicolumn{9}{|l|}{ Doubles } \\
\hline U15 & 35 (48.6) & $24(33.3)$ & $7(9.7)$ & $6(8.3)$ & 72 & 32.778 & $<.001$ & .39 \\
\hline U17 & $34(47.2)$ & $19(26.4)$ & $14(19.4)$ & $5(6.9)$ & 72 & 24.556 & $<.001$ & .34 \\
\hline Junior (U19) & $24(33.3)$ & $26(36.1)$ & $17(23.6)$ & $5(6.9)$ & 72 & 15.000 & .002 & .26 \\
\hline Total & 93 (43.1) & 69 (31.9) & $38(17.6)$ & $16(7.4)$ & 216 & 63.815 & $<.001$ & .31 \\
\hline
\end{tabular}

Note. Q1, Q2, Q3, Q4 = birth quarters. 
Table 3 Odds ratios (and the $95 \%$ confidence intervals) examining birth month distributions between quartiles by categories

\begin{tabular}{lccc}
\hline \multicolumn{1}{c}{ Q1 vs. Q4 } & Q2 vs. Q4 & Q3 vs. Q4 \\
\hline U15 & & & \\
Singles & $13.00[1.27,133.28]$ & $5.00[0.44,56.62]$ & $5.00[0.44,56.62]$ \\
$\quad$ Doubles & $5.83[1.97,17.26]$ & $4.00[1.32,12.11]$ & $1.17[0.33,4.16]$ \\
$\quad$ Total & $6.86[2.59,18.16]$ & $4.14[1.52,11.27]$ & $1.71[0.58,5.10]$ \\
U17 & & & \\
Singles & $4.00[0.59,27.25]$ & $4.00[0.59,27.25]$ & $3.00[0.42,21.3]$ \\
$\quad$ Doubles & $6.80[2.17,21.34]$ & $3.80[1.17,12.39]$ & $2.80[0.83,9.41]$ \\
$\quad$ Total & $6.00[2.25,15.99]$ & $3.86[1.41,10.54]$ & $2.86[1.02,8.00]$ \\
Junior (U19) & & & \\
$\quad$ Singles & $4.45[0.67,37.24]$ & $4.45[0.67,37.24]$ & $2.00[0.26,15.38]$ \\
$\quad$ Doubles & $6.40[2.04,20.03]$ & $6.93[2.23,21.58]$ & $4.53[1.41-14.6]$ \\
$\quad$ Total & $4.71[1.75,12.72]$ & $5.00[1.86,13.45]$ & $3.00[1.08,8.37]$ \\
Total & & & \\
Singles & $6.00[1.9,18.95]$ & $4.40[1.37,14.18]$ & $3.00[0.90,10.01]$ \\
$\quad$ Doubles & $5.81[3.03,11.14]$ & $4.31[2.22,8.36]$ & $2.38[1.18,4.76]$ \\
$\quad$ Total & $5.86[3.32,10.32]$ & $4.33[2.44,7.71]$ & $2.52[1.38,4.61]$ \\
\hline
\end{tabular}

Note. Q1, Q2, Q3, Q4 = birth quarters.

Figure 1 Quarterly distribution of award-winning athletes' birth months by age tournaments, type of medals and categories
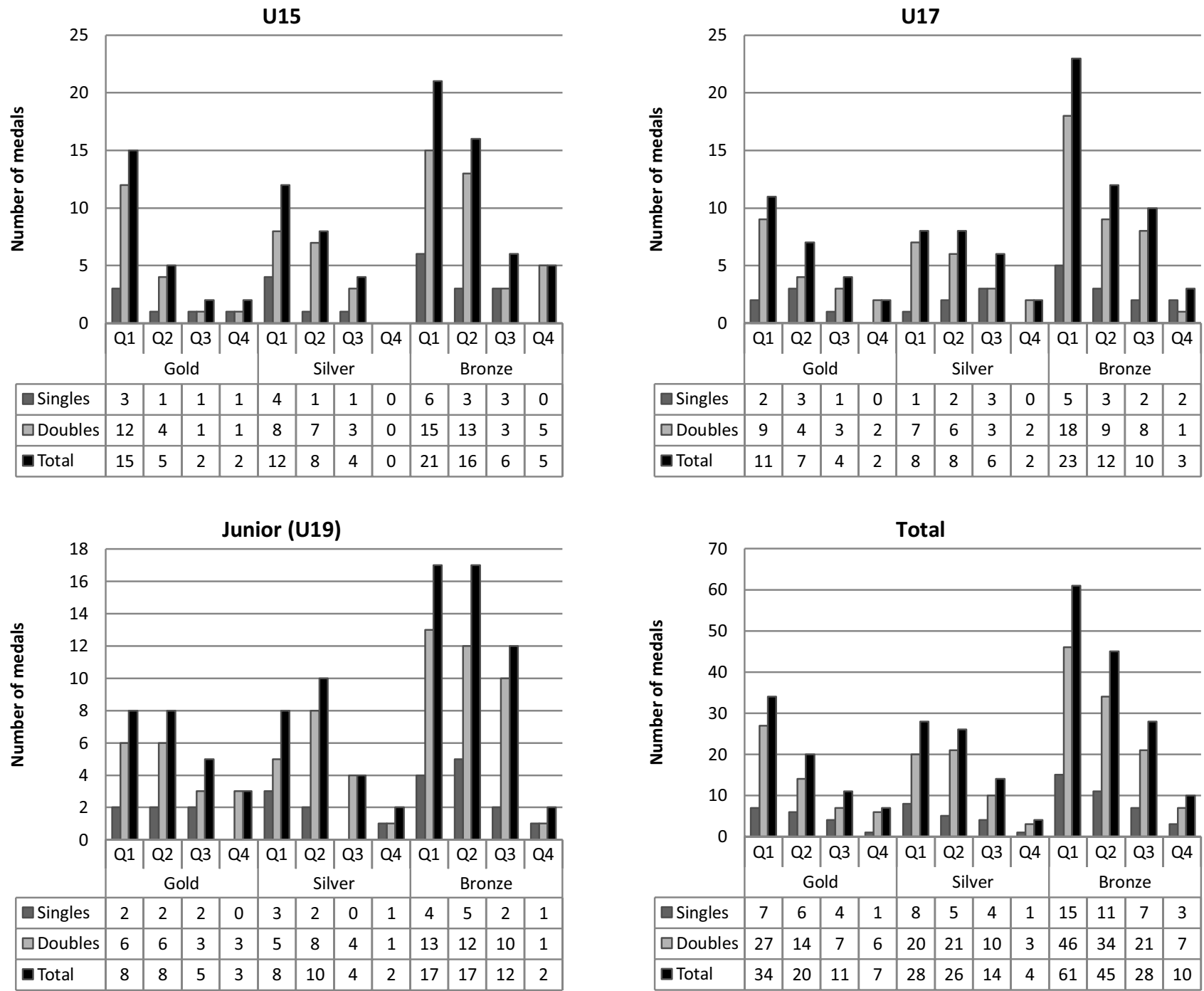

Note. Q1, Q2, Q3, Q4 = birth quarters. 
of relative age phenomena by Wattie et al. (2015). It is stressed in this model that individual (e.g., birthdate, sex, physical maturation and size), environment (e.g., age and other grouping policies, family influence, popularity of sport and coach influence) and task (e.g., physicality of sport, laterality advantage, participation level and playing position) interact with each other, and this interaction causes the RAE. Moreover, success is shaped through this interaction over the years accordingly, because, each of the three factors has great impact on success by different perspectives.

As heavily suggested in the relevant literature, skewed distribution determined in this study can be a result of physical and physiological differences caused by varied maturational time changes of each individual (Musch \& Grondin, 2001). Better endurance, muscular strength, aerobic power and speed provide advantages in many sports (Malina et al., 2007), and adolescence is particularly the period of development of strength, change in absolute aerobic power and peak height velocity as stated by Beunen and Malina (2008). Furthermore, psychological aspects and motor readiness may vary in relation with relative age too (Baxter-Jones, 1995; Musch \& Grondin, 2001). Thus, the maturational advantage of relatively older athletes might be addressed to explain success in the youth sporting context.

Besides those advantages of relatively older athletes, Ford and Williams (2011) investigated the RAE in the birthdates of award-winning athletes, which is an indication of skillfulness, proficiency and success, in male professional soccer, ice hockey, baseball and Australian football players. No over-representation of relatively older or younger athletes was noted in their study when holding the distribution theoretically equal. However, when positively skewed distribution of general population favouring relatively older players was accepted as theoretically expected values in the analyses, award-winning athletes were determined more likely to be born late. It is also stated that relatively younger players must develop some other performance advantages such as skill and technique to survive, which fairly explains their earned place in the system.

On contrary of the results mentioned above, in individual sports and specifically racket sports, similar findings to ours were noted in the relevant literature. Faber, Liu, et al. (2020) reported the statistically significant over-representation of Q1 table tennis players in U15 category in Europe and in U15 and U18 categories in France compared to the players in Q4. Edgar and O'Donoghue (2015) investigated the RAE among elite tennis players (448 seniors in Grand Slams and 476 juniors achieving at least 120 points), and pointed out the statistically significant RAEs among both seniors and juniors. A more recent study in tennis by Gerdin et al. (2018) points out similar trends among 1835 "ranked" Swedish junior tennis players regarding the RAE. Furthermore, Ferriz-Valero, García Martínez, et al. (2020) conducted a research on RAE among young triathletes participating in Valencian Triathlon League between 20122016, and the medal owners. A bias favouring early born athletes was determined, and regarding the type of medal, athletes born in Q1 dominated the gold medals in particular. Several similar results were noted in other individual sports too (Brustio et al., 2019; Raschner et al., 2012; Romann \& Cobley, 2015). Thus, these results address that our findings are in line with the previous studies on racket sports and individual sports in general. Moreover, with regard to gender, in our study RAE among females were stronger considering the effect sizes. Similar findings related to females were also mentioned among young elite tennis players by Gerdin et al. (2018). Smith et al. (2018) also mentioned the RAE among females. In their systematic review and meta-analysis on females sporting context, RAE was pointed out as more prevalent during adolescent categories with a decreasing trend during post-adolescence and becoming insignificant after all. Our findings on that decreasing trend also support this systematic review and meta-analysis results.

The findings of the current study suggest statistically significant presence of RAE in award-winning badminton players in favour of relatively older players. This result may be corroborated through several explanations based on maturation, experience and level of competition. However, continuation of this advantageous position of relatively older players might be stated as a more striking result. In all age categories, RAE is present significantly, yet a tendency to decrease is also evident as is seen from effect size values. However, in order to propound a more general statement besides the youth badminton players, further research is required to be conducted for current condition of RAE in adulthood, because in adulthood, several physical and physiological capabilities become more homogenous in elite level (Franks et al., 1999), while adolescence is characterized as the period of development of strength, change in aerobic power and peak height velocity as stated by Beunen and Malina (2008), and time and tempo differences should be taken into consideration in this process (Malina et al., 2004). As a result, the criteria used to select athletes at younger ages may differ from adult athletes which set the basis of RAE. Since already-selected players in younger ages are very well-known to coaches, reselection is another important subject, and it might be seen as an ever-repeating phenomenon in adulthood (Vincent \& Glamser, 2006), which may cause loss of great talents since they are not selected at younger ages because of their difference in time and tempo related maturational developments compared to their peers. Here, coaches are better to decide whether their purpose is to select or develop talent.

In particular, while aiming for success (on short term), relatively older players are more likely to be selected to the national teams considering the aforementioned advantages related to maturation compared to relatively younger peers. Especially in youth categories, these maturation differences may ensure temporary advantages through a specific period which may bring the success and medal. Similar to other racket sports like table tennis (Faber, Liu, et al., 2020) and tennis (Jayanthi et al., 2011), badminton is an early entry sport. Gao (2017) reported that $75 \%$ of Chinese players specialized in badminton between $10-12$ and $25 \%$ players specialized between $7-9$, while $60 \%$ of British players specialized between 10-12 years of age in her studies' sampling. This is really an early period compared to Bompa 
and Buzzichelli's (2019) guide for age to start specialization in badminton. In youth sport, biological age plays a key role. For instance, Malina et al. (2000) found a dramatic scenario among 15-16 years old soccer players that only $2 \%$ of them were late maturing while $65 \%$ of them were early maturing athletes. Thus, relatively older players may become prominent with their more mature physical abilities, psychological skills and experience against their same age peers (Musch \& Grondin, 2001). This idea perfectly fits in our context while discussing our findings indicating the relatively older players' dominance in medals in such a demanding level of European Championships of youth categories in badminton.

Cobley et al. (2009) suggested the increase of RAE as the level of competition increases. So, this skewed distribution determined in the current study could be regarded as a reflection of the level of competitors since they are elite athletes representing their countries in a continent championship. Gerdin et al. (2018) also noted in their study on young tennis players that as the rankings of players was higher up, greater RAEs were determined. In this study, they reported that $60.2 \%$ of players of the "top 50 players" were born in the first six months of the year, while for the "top 10 players", $64.1 \%$ of the players were born in the first half of the year. Moreover, Romann and Cobley (2015) also stated that RAE effect sizes are becoming stronger as the performance level has increased (i.e., comparison of all athletes vs. Top 10\%). Similarly, Smith et al. (2018) reported the competition level as a determinant in competitive elite level with the presence of RAE, and Faber, Liu, et al. (2020) also stressed the importance of the level of athletes while discussing the RAE among table tennis players. Thus, our findings might be suggested as in line with such findings considering that we investigated such a high level as European Championships, and the national teams consist of the best players of the countries.

In badminton, only Nakata and Sakamoto (2011, 2012) investigated the RAE among badminton players, yet no RAE was determined in both studies which is contrary to our findings to a certain extent. The differences in the nature of these two studies and ours are better to be taken into consideration while comparing the results. In one of the study, a total of 146 badminton players were evaluated, yet they were stated as amateur badminton players (Nakata \& Sakamoto, 2011). In the other study, among the total of 279 badminton players competing in the top Japanese leagues, no RAE was noted either (Nakata \& Sakamoto, 2012). However, neither of the studies specified age categorisation among these players while we only included the medal winner elite youth European badminton players. So, the sampling characteristics of these studies are quite different from ours' which might be the underlying cause of different results regarding the presence of RAE.

It should be considered as limitation, that in this study, only the last three consecutive European U15, U17 and Junior Badminton Championships were included, thus the sampling is limited to the results of these tournaments. Hence, conducting research with more participants might explain the phenomenon better. This study is also limited considering that only youth categories have been investigated. The situation among adults might also be a question for further studies in RAE. Also fact that some players reached the podium in two disciplines could be considered as another limitation; however, the number of these players was relatively low. Lastly, conducting research on different sports in the future might be beneficial in order to get deeper knowledge on RAE because of their different performance demands and characteristics.

\section{Conclusions}

This study has revealed the current status of European elite youth badminton players with regard to RAE. Statistically significant results in favour of relatively older badminton players were determined in the current study among awardwinning athletes in three consecutive European U15, U17 and Junior Badminton Championships. In general, players in Q1 are more than five times as likely to reach the podium than players in Q4. So, RAE is better to be considered more than just participation bias contrary to many studies in the relevant literature. It seems to have an explicit role regarding success which is a key tenet of elite sport.

In practice, selection criteria and competition rules (i.e., age-grouping system) are better to be taken into reconsideration to give equal opportunities to each athlete for participation, selection and success. Coaches should be enlightened regarding the talent identification and selection by accepting it as a process instead of a point in the continuum. Athletes' development should be considered over this continuum, and possible maturation differences are better to be kept in mind while deciding on talent. Through this, the loss of talent could be prevented.

\section{Conflict of interest}

The authors report no conflict of interest.

\section{References}

Arrieta, H., Torres-Unda, J., Gil, S. M., \& Irazusta, J. (2016). Relative age effect and performance in the U16, U18 and U20 European Basketball Championships. Journal of Sports Sciences, 34(16), 1530-1534. https://doi.org/10.1080/02640414 .2015 .1122204

Barnsley, R. H., Thompson, A. H., \& Barnsley, P. E. (1985). Hockey success and birthdate: The relative age effect. Canadian Association for Health, Physical Education, and Recreation Journal, 51(8), 23-28.

Baxter-Jones, A. D. (1995). Growth and development of young athletes. Should competition levels be age related? Sports Medicine, 20(2), 59-64. https://doi. org/10.2165/00007256-199520020-00001

Beunen, G., \& Malina, R. M. (2008). Growth and biologic maturation: Relevance to athletic performance. In H. Hebestreit \& O. Bar-Or (Eds.), The young athlete (pp. 3-17). John Wiley \& Sons. https://doi.org/10.1002/9780470696255.ch1

Bompa, T. O., \& Buzzichelli, C. A. (2019). Periodization: Theory and methodology of training (6th ed.). Human Kinetics.

Bruner, M. W., Macdonald, D. J., Pickett, W., \& Côté, J. (2011). Examination of birthplace and birthdate in world junior ice hockey players. Journal of Sports Sciences, 29(12), 1337-1344. https://doi.org/10.1080/02640414.2011.597419

Brustio, P. R., Kearney, P. E., Lupo, C., Ungureanu, A. N., Mulasso, A., Rainoldi, A., \& Boccia, G. (2019). Relative age influences performance of world-class track and field athletes even in the adulthood. Frontiers in Psychology, 10, Article 1395. https://doi.org/10.3389/fpsyg.2019.01395

Cobley, S., Baker, J., Wattie, N., \& McKenna, J. (2009). Annual agegrouping and athlete development: A meta-analytical review of relative age effects in sport. Sports Medicine, 39(3), 235-256. https://doi. org/10.2165/00007256-200939030-00005

Delorme, N., \& Raspaud, M. (2009). The relative age effect in young French basketball players: A study on the whole population. 
Scandinavian Journal of Medicine \& Science in Sports, 19(2), 235-242. https:// doi.org/10.1111/j.1600-0838.2008.00781.x

Edgar, S., \& O'Donoghue, P. (2005). Season of birth distribution of elite tennis players. Journal of Sports Sciences, 23(10), 1013-1020. https://doi org/10.1080/02640410400021468

Faber, I. R., Liu, M., Cece, V., Jie, R., Martinent, G., Schorer, J., \& Elferink-Gemser, M. T. (2020). The interaction between within-year and between-year effects across ages in elite table tennis in international and national contexts - A further exploration of relative age effects in sports. High Ability Studies, 31(1), 115-128. https://doi.org/10.1080/13598139.2019.1596071

Faber, I. R., Martinent, G., Cece, V., \& Schorer, J. (2020). Are performance trajectories associated with relative age in French top 100 youth table tennis players? - A longitudinal approach. PLOS ONE, 15(4), Article e0231926. https://doi. org/10.1371/journal.pone.0231926

Ferriz-Valero, A., García Martínez, S., Olaya-Cuartero, J., \& García-Jaén, M. (2020). Sustainable sport development: The influence of competitive grouping and relative age on the performance of young triathletes. Sustainability, 12(17), Article 6792. https://doi.org/10.3390/su12176792

Ferriz-Valero, A., Sellés-Pérez, S., García-Jaén, M., \& Cejuela, R. (2020). Efecto de la edad relativa para el desarrollo del talento en jóvenes triatletas [Relative age effect for talents' development in young triathletes]. Retos, 37, 27-32. https:// doi.org/10.47197/retos.v37i37.67384

Ford, P. R., \& Williams, M. A. (2011). No relative age effect in the birth dates of award-winning athletes in male professional teamsports. Research Quarterly for Exercise and Sport, 82(3), 570-573. https://doi.org/10.1080/02701367.2011.10 $\underline{599790}$

Franks, A. M., Williams, A. M., Reilly, T., \& Nevill, A. (1999). Talent identification in elite youth soccer players: Physical and physiological characteristics. Journal of Sports Sciences, 17(10), 812.

Gao, R. Y. (2017). A comparison between Talent Identification and Development (TID) for badminton in China and the UK. [Master's thesis, The University of Stirling, Stirling, United Kingdom]. Stirling Online Research Repository. https:// dspace.stir.ac.uk/handle/1893/25675\#.YAQrVXYzblU

Gerdin, G., Hedberg, M., \& Hageskog, C. (2018). Relative age effect in Swedish male and female tennis players born in 1998-2001. Sports, 6(2), Article 38 https://doi.org/10.3390/sports6020038

Grondin, S., Deshaies, P., \& Nault, L. P. (1984). Trimestre de naissance et participation au hockey et au volleyball [Birth term and participation in hockey and volleyball]. Le revue Québécoise de l'activité physique, 2, 97-103.

Hancock, D. J., Adler, A. L., \& Côté, J. (2013). A proposed theoretical model to explain relative age effects in sport. European Journal of Sport Science, 13(6), 630-637. https://doi.org/10.1080/17461391.2013.775352

Helsen, W. F., Starkes, J. L., \& van Winckel, J. (1998). The influence of relative age on success and dropout in male soccer players. American Journal of Human Biology, 10(6), 791-798. https://doi.org/10.1002/ (SICI)1520-6300(1998)10:6<791::AID-AJHB10>3.0.CO;2-1
Helsen, W. F., van Winckel, J., \& Williams, A. M. (2005). The relative age effect in youth soccer across Europe. Journal of Sports Sciences, 23(6), 629-636. https:// doi.org/10.1080/02640410400021310

Jayanthi, N. A., Dechert, A., Durazo, R., \& Luke, A. (2011). Training and specialization risks in junior elite tennis players. Journal of Medicine and Science in Tennis, 16(1), 14-20.

Malina, R. M., Bouchard, C., \& Bar-Or, O. (2004). Growth, maturation, and physical activity (2nd ed.) Human Kinetics.

Malina, R. M., Peña Reyes, M. E., Eisenmann, J. C., Horta, L., Rodrigues, J., \& Miller, R. (2000). Height, mass and skeletal maturity of elite Portuguese socce players aged 11-16 years. Journal of Sports Sciences, 18(9), 685-693. https:// doi.org/10.1080/02640410050120069

Malina, R. M., Ribeiro, B., Aroso, J., \& Cumming, S. P. (2007). Characteristics of youth soccer players aged 13-15 years classified by skill level. British Journal of Sports Medicine, 41(5), 290-295. https://doi.org/10.1136/bjsm.2006.031294

Musch, J., \& Grondin, S. (2001). Unequal competition as an impediment to personal development: A review of the relative age effect in sport. Developmenta Review, 21(2), 147-167. https://doi.org/10.1006/drev.2000.0516

Nakata, H., \& Sakamoto, K. (2011). Relative age effect in Japanese male athletes. Perceptual and Motor Skills, 113(2), 570-574. https://doi.org/10.2466/05.10.11. pms.113.5.570-574

Nakata, H., \& Sakamoto, K. (2012). Sex differences in relative age effects among Japanese athletes. Perceptual and Motor Skills, 115(1), 179-186. https://doi org/10.2466/10.05.17.pms.115.4.179-186

Raschner, C., Müller, L., \& Hildebrandt, C. (2012). The role of a relative age effect in the first winter Youth Olympic Games in 2012. British Journal of Sports Medicine, 46(15), 1038-1043. https://doi.org/10.1136/bjsports-2012-091535

Romann, M., \& Cobley, S. (2015). Relative age effects in athletic sprinting and corrective adjustments as a solution for their removal. PLOS ONE, 10(4), Article e0122988. https://doi.org/10.1371/journal.pone.0122988

Smith, K. L., Weir, P. L., Till, K., Romann, M., \& Cobley, S. (2018). Relative age effects across and within female sport contexts: A systematic review and meta-analysis. Sports Medicine, 48(6), 1451-1478. https://doi.org/10.1007/ $\underline{\text { s40279-018-0890-8 }}$

Turnnidge, J., Hancock, D. J., \& Côté, J. (2012). The influence of birth date and place of development on youth sport participation. Scandinavian Journal of Medicine \& Science in Sports, 24(2), 461-468. https://doi.org/10.1111/sms.12002

Vincent, J., \& Glamser, F. D. (2006). Gender differences in the relative age effect among US olympic development program youth soccer players. Journal of Sports Sciences, 24(4), 405-413. https://doi.org/10.1080/02640410500244655

Wattie, N., Schorer, J., \& Baker, J. (2015). The relative age effect in sport: A developmental systems model. Sports Medicine, 45(1), 83-94. https://doi.org/10.1007/ s40279-014-0248-9

Weir, P. L., Smith, K. L., Paterson, C., \& Horton, S. (2010). Canadian women's ice hockey evidence of a relative age effect. Talent Development and Excellence, 2(2), 209-217. 